\title{
Anatomy Word-Learning in Undergraduate Speech-Language Pathology Students
}

Janie L. Kullmar

Middle Tennessee State University, jlk6g@mtmail.mtsu.edu

Kathryn G. Blankenship

Middle Tennessee State University, kathryn.blankenship@mtsu.edu

DOI: https://doi.org/10.30707/TLCSD4.1/KQZG7225

Follow this and additional works at: https://ir.library.illinoisstate.edu/tlcsd

Part of the Curriculum and Instruction Commons, and the Social and Behavioral Sciences Commons

\section{Recommended Citation}

Kullmar, Janie L. and Blankenship, Kathryn G. (2020) "Anatomy Word-Learning in Undergraduate SpeechLanguage Pathology Students," Teaching and Learning in Communication Sciences \& Disorders: Vol. 4: Iss. 1 , Article 5. DOI: https://doi.org/10.30707/TLCSD4.1/KQZG7225

Available at: https://ir.library.illinoisstate.edu/tlcsd/vol4/iss1/5

This Student Voices is brought to you for free and open access by ISU ReD: Research and eData. It has been accepted for inclusion in Teaching and Learning in Communication Sciences \& Disorders by an authorized editor of ISU ReD: Research and eData. For more information, please contact ISUReD@ilstu.edu. 


\title{
Anatomy Word-Learning in Undergraduate Speech-Language Pathology Students
}

\begin{abstract}
This study compared the effectiveness of a vocabulary list (i.e., explicit environment) to a textbook passage (i.e, authentic environment) for the initial exposure of domain-specific vocabulary from an anatomy textbook. Forty-two undergraduate Speech-Language Pathology students participated. The study's materials are from Anatomy and Physiology for Speech Language and Hearing, fifth edition (Seikel et al., 2016). The selection is a subtopic on the topic of the anatomy of the cerebrum. Twenty-five vocabulary words within this section are bolded by the textbook to emphasize their importance. These words were targeted in the two different conditions, authentic (textbook) and explicit (vocabulary list). The gain scores from pretest to posttest between groups (i.e., authentic vs. explicit) were similar, and this was true of students with both high and low reading abilities, as measured by the reading score from the American College Testing (ACT). Student performance was highly variable, and many students performed poorly regardless of condition. The results of the study revealed no significant differences between participants who were in conditions that received vocabulary words within the context of a textbook or isolated in a list. This poor performance may be related to research design or student reading habits in general.
\end{abstract}

Keywords

word-learning, undergraduate students 
The wide scope of practice and the complexity associated with the field of speech-language pathology requires students to understand concepts from multiple disciplines. This is seen in the standards for certification where applicants must display "knowledge of basic human communication and swallowing processes, including the appropriate biological, neurological, acoustic, psychological, developmental, and linguistic and cultural bases..." (Council for Clinical Certification in Audiology and Speech-Language Pathology [CFCC], 2016, n.p.). Professors of Speech-Language Pathology are tasked with teaching novel words from many disciplines.

This study explores the initial introduction of complex material, specifically anatomy and physiology, to undergraduate students majoring in speech-language pathology and audiology. This is important because current research on college students reveals that reading abilities are declining (Baer et al., 2006; Chall, 1996; Sanchez, 2013; Turnbull, 1985). When students struggle with reading comprehension, their ability to learn is impeded because more working memory is being used to decode information (Cowan, 2014). This study aims to help these students by exploring the effectiveness of introducing students to the pertinent vocabulary, which is the keystone of comprehension (Laufer \& Ravenhorst-Kalovski, 2010). Introducing students to the required vocabulary is simple, because it is often already emphasized stylistically in textbooks, through highlighted or bold text. After preparation with the required vocabulary words, students will hopefully tackle corresponding material more easily.

\section{Literacy in the Content Areas}

Research on literacy in the content areas, is both important for speech-language pathology education, and for speech-language pathology intervention. A well-trained speech-language pathologist is uniquely qualified to inform educators about language in the school environment, particularly when language skills extend beyond the language and reading classrooms (ASHA, 2012). Content-area research also directly relates to the speech-language pathologists' work in the high-school setting (ASHA, 2012; Zygouris-Coe \& Goodwiler, 2013). Therefore, researching effective ways to present information to students in speech-pathology classes can not only inform professors, but speech-language pathologists addressing literacy in other settings.

Content area research examines the academic language used outside of the language arts classroom. Academic language is defined by Nagy and Townsend (2012) as "the specialized language, both oral and written, of academic settings that facilitates communication and thinking about disciplinary content" (p.92). These texts are distinctive in that they contain complex syntax, a high degree of low incidence words and a large amount of novel words that are specific to the subject (Burton, 2014; Nagy \& Townsend, 2012). This sophistication poses a challenge for students, especially in consideration of recent declines in reading competency. Chall (1996) reports that research on reading competency revealed a downward trend for students at the elementarylevel and through late high-school from the 1980's to late 1990's. The trend is prevalent among college students as well. In 2006, a study of over 1000 students from four-year and two-year institutions found that while college students had higher reading levels than the national average, 20 to 30 percent had basic or low literacy comprehension (Baer, Cook, \& Baldi, 2006). The College Board, which produces an eminent college entrance exam, the SAT, announced concern after the SAT revealed that six out of ten college bound seniors in 2013 were not ready for college level material (Sanchez, 2013). If reading levels are low, textbook comprehension will be as well, thus, 
compromising college students' ability to learn material from difficult books, such as textbooks.

Anatomy and physiology instruction is among the most difficult academic area to learn, with a high degree of novel words. Research on the topic has focused on innovative instructional methods, such as computer programs and surface anatomy modules (Skinder-Meredith, 2010). Seikel, Drumright, and King (2016) have adapted computer software for their anatomy textbook since its first edition in the late 1990's. Despite the advancements in computer and visual aids, lectures and textbooks remain the mainstay of anatomy and physiology instruction; however, little research has focused on textbook assignments (Skinder-Meredith, 2010).

\section{Textbook Assignments}

Textbook assignments prior to lecture are an expectation in science, business, psychology, and math courses at the college level (Aagaard, Conner, \& Skidmore, 2014; Bartolomeo-Maida, 2016; Heiner, Banet, \& Wieman, 2014; Phillip \& Phillips, 2007). Despite these assignments, research shows that students do not read from the textbook regularly. A longitudinal study of college psychology classes from 1981 to 1997 found that each year fewer and fewer students complete reading assignments, which researchers described as a "disturbing trend of noncompliance" (Burchfield \& Sappington, 2000, p. 59). Students are failing to complete reading assignments, which is limiting their ability to ask important questions and keep up with the demands of lectures and tests.

Students with poor grade point averages (GPAs) have the highest prevalence of skipping reading assignments; however, even high performing students fail to read from textbooks prior to class (Phillip \& Phillips, 2007). While much of this trend can be explained simply as student behavior, other reasons may be at play. One such reason, perhaps particularly for students of low reading levels, is the complexity of the language within the textbook. Textbook language is categorized under the classically difficult genre of academic language (Aagaard et al., 2014; Berry, Cook, Hill, \& Stevens, 2011).

In order to combat problems related to reading competency decline, and related lack of adherence to reading assignments, researchers have examined introductions to complex material. Researchers that used textbooks in experiments reported that students performed poorly when asked to summarize and then apply information from a scientific passage (Mayer, Bove, Bryman, Mars, \& Tapangco, 1996). Researchers compared the knowledge gained when students were given a multimedia summary, a text with a multimedia summary, or just a text passage. The multimedia summary consisted of five images with short explanations. Students performed best on a quiz of material content when given only the multimedia summary (Mayer et al., 1996). When asked to apply information, students who had received the multimedia summary and the passage performed at the same levels as the students with just the multimedia summary, but at a lower level than those who only received the passage. When the text in the multimedia summary was increased recall scores fell (Mayer et al., 1996). These findings indicate that simplified initial instruction is an effective learning strategy.

Another basic introduction to complex material that might be particularly suited to word-dense fields, such as anatomy, could be to explicitly introduce the novel words within the section. Novel 
word assignments could also provide students with more clarity about their responsibilities for class, and prepare them for lecture or reading assignments. Their word knowledge in the past will then guide them as they learn new material. Knowledge repetition is important when acquiring new information, and as such professors often delay quizzes until after material has been presented. However, this may lead to poor compliance with reading activities. If this method allows students to better learn independently, professors could quiz students, thereby holding students accountable for the material they are assigned.

Vocabulary acquisition is key to comprehension of new material and the basis of reading comprehension (Laufer \& Ravenhorst-Kalovski, 2010). The simplification of vocabulary within a textbook was found to improve course grades in a college biology class, which indicates that vocabulary can greatly improve student understanding and performance (Schoerning, 2014). This is not feasible for many textbooks and classes, but indicates that vocabulary could be the key to improved comprehension of complex materials.

A list of vocabulary words could serve as an appropriate initial exposure to the words. Explicit vocabulary instruction is only the beginning of instruction. Vocabulary acquisition requires multiple exposures within authentic environments (i.e., textbooks) and is further supported by the usage of novel words (Nagy \& Townsend, 2012). Students should work with novel words in lecture, while reading, during class discussion, and in written class assignments. Teaching vocabulary outside of its authentic context may present unique disadvantages. One potential disadvantage may be that simplifying assignments given to students could diminish the amount that they are forced to grapple with complex texts. Definition activities are textually explicit, meaning that they do not require students to engage with material or use inference skills from the texts (Ornstein, 1994). The ability to learn from academic language is an important skill for students to build throughout their education. After graduation, speech-language pathologists must independently read new research in order to apply new research on therapy, treatment techniques and evidence-based practices. Explicit vocabulary instruction does not provide students with the practice of discerning information from complex texts, or contextual information.

Despite these disadvantages, the process of word-learning prior to lecture and textbook assignments may be necessary to understand texts that are filled with novel words. If students are able to completely understand texts, they will be prepared to apply critical thinking skills. This word-learning process gives students the ability to improve instruction beyond the basic educational questions that critics of textbook-reliance deride as "right answer oriented" questions (Ornstein, 1994, p.72). Ornstein's (1994) review of this literature emphasized that students should learn to read in order to infer and connect.

This study compared undergraduate speech-language pathology students' performance on an academic task of defining target vocabulary after either seeing the definitions of the words within an authentic context (i.e., textbook) or after being given the words with more explicit instruction (i.e., vocabulary list with definitions). The research poses two questions. 
1. Do students learn anatomy and physiology vocabulary better from a definition list compared to reading them within the textbook?

Hypothesis 1: Vocabulary lists have simpler language levels and present a less demanding cognitive load. Therefore, the students who read the explicit word learning contexts (i.e., vocabulary list) will recall more information than the students who read the words in an authentic contexts (i.e., textbook).

2. Do students with lower reading levels, as measured by their ACT scores, more closely match higher-reading level peers when given a vocabulary list instead of a textbook selection?

Hypothesis 2: Students who struggle with reading comprehension will remember less from the authentic condition (i.e., textbook) than their peers with higher reading comprehension scores, but will perform at similar levels when given the explicit condition (i.e., vocabulary list).

\section{Methods}

Participants. The study recruited 44 participants, which were undergraduate Speech-Language Pathology majors. Two students were not included in the data analysis because one did not complete the post-test and the other was not a Speech-Language Pathology major. This left 42 participants. All of the participants were female. Demographic information about the participants' mean ages, GPAs, and ACT scores are included in Table 1. The researchers checked the participants' ACT score in their department's demographic database to ensure that reported ACT scores were accurate. There was 100\% agreement between the students' reported ACT scores compared to the departments' demographic database.

Participants were assigned to one of two reading level groups based on their self reported Reading ACT score (i.e., high ACT and low ACT) in a counter balance fashion (all ACT scores were later verified and were $100 \%$ accurate). The ACT score was used because it is roughly correlated with reading abilities (Snowman, Leitner, Snyder, \& Lockhart, 1980; Stiggins, Schmeiser, \& Ferguson, 1978). The average ACT score at Middle Tennessee State University is a 22, this was used as the cutoff point to divide students into two reading level groups. Students with a 22 or lower ACT score were characterized as having a low score, while students with 23 and higher were characterized as having a high ACT score. Students in the low reading group had an average ACT score of $20.15(n=19)$. Students in the high reading group had an average ACT score of 26.28 $(n=17)$.

Material. The study's materials are from Anatomy and Physiology for Speech Language and Hearing, fifth edition (Seikel et al., 2016). This textbook is used within Middle Tennessee's Speech-Language Pathology and Audiology program for two classes, CDIS 3400 - Anatomy and Physiology for Speech Pathology, and CDIS 4400 - Neurology for Speech Pathology and Audiology. This textbook was designed for undergraduates and graduate speech-language pathology students (Seikel et al., 2016). The selection is a subtopic on the topic of the anatomy of the cerebrum. This particular selection was chosen because it is not extensively covered in the program, ensuring that the words and subject material are unfamiliar to the participant at the time 
of the experiment. This was verified by pre-test performance, where the average score was three percent. Twenty-five vocabulary words within this section are bolded by the textbook to emphasize their importance. These words were targeted in the two different conditions, which are discussed below.

The authentic context (i.e., textbook). Participants received the text and images from the passage in their entirety. Asides about the clinical applications were removed. The 25 targeted vocabulary words appear in the textbook as bolded vocabulary and remain bold in the textbook selection.

The explicit condition (i.e., vocabulary list). Participants received the bolded words from the text compiled into a vocabulary list. Definitions for the words are from the glossary of the same textbook. The words were given in the same order as they appear in the textbook. The photos and diagrams in the book were included in approximately the same place as the placement of the images in the textbook.

Procedures. Participants were recruited from three of the Speech-Language Pathology and Audiology summer classes, and through a departmental email. Participants came into the Speech, Language and Hearing clinic at Middle Tennessee State University. The students agreed to participate in the study via an informed consent form. The participants were then given a demographic form and pre-test. Participants were asked in the pre-test to define each of the words by writing out a definition of the targeted vocabulary words.

Testing Sequence. The participants then received a packet containing the testing stimuli for one of the conditions (i.e., authentic or explicit). The packet contained either the pages from an anatomy textbook (authentic condition) or a list of 25 words with definitions (explicit condition). The participants read through the packet of materials once. After participants received the reading material the test facilitator gave participants a brief survey on their perception of the testing material and on their own reading and study habits. After the participants completed the survey, they were given the pre-test again to assess improvement, which is the post-test. After the posttest, a second survey was given to the students about their opinion on the testing procedures, and questions on reading habits aside from school commitments. The surveys provide the researchers with descriptive information about the participants' general reading habits.

Scoring. To establish a scoring criterion, the researcher identified the individual pieces of information contained in the conditions. For example, the definition for arachnoid mater from the authentic condition stated, "The arachnoid mater is a covering through which many blood vessels for the brain pass. The arachnoid lining is a lacey, spiderlike structure separating the dura mater from the innermost meningeal lining" (Seikel et al., 2016, p. 599). The definition from the explicit condition stated that the arachnoid mater was "a meningeal lining located between dura and pia mater, consisting of lacey, spiderlike fibers" (Seikel et al., 2016, p. 801). The researcher identified three pieces of information from the above conditions. Students received one point for listing any of the following pieces of information: 1 . It is a meningeal lining; 2. Its location (the students could say that it is between dura and pia, the middle layer or below dura above pia); 3 . The material, it is lacey/spider-like. Each piece of information that the participant stated was awarded one point. The researcher found 70 pieces of information for the 25 words. The researcher graded the words using the grading criterion for both the pre- and posttest conditions. The researcher was blind to 
the test condition during the grading process. For reliability, a student research assistant graded $10 \%$ of the participant responses using a rubric defining points awarded for each individual piece of information. The researcher and assistant achieved 86\% agreement on scoring. On the items that were in disagreement the researcher and student research assistant discussed differences and came to $100 \%$ agreement. To prepare the data for statistical analyses, the researcher calculated gain scores by subtracting the pre-test score from the post-test score. The statistical analysis used was a one-way ANOVA to compare the difference in performance between the pretest and posttest between the two experimental conditions (i.e., authentic and explicit). An ANCOVA was used to evaluate the difference in performance on the posttest measure between individuals with high ACT scores and low ACT scores. A p level <.001 was considered significant.

To analyze the participants' feedback of testing material and students' reading habits, a Pearson product-moment correlation coefficient and an independent t-test were used. The following three Pearson product-moment correlation coefficient analyses were conducted: 1) to assess the relationship between gain score and perceived difficulty then for ACT reading score and perceived difficulty; 2) to assess the relationship between gain score and ACT reading score; and 3) to assess the relationship between ACT reading score and the student's interest in the testing material. An independent t-test was used to assess the difference between the two groups' perceived difficulty of the reading material. A p level $<.001$ was considered significant.

\section{Results}

Prior to any statistical analyses the researchers evaluated three demographic variables (i.e., age, GPA and ACT scores) between the two treatment groups (i.e., authentic and explicit) to ensure that there were not any potential difference between them. Independent $t$ tests were used to compare the means between the treatment groups on the three variables. For the significant variables, ACT, GPA, and Reading ACT score, the two treatment groups did not have significant differences between them. Therefore, it can be assumed that the treatment groups are equal on these variables (See Table 1).

The first research question asked if students learn anatomy and physiology vocabulary better from a definition list (i.e., explicit condition) compared to reading them within the textbook (i.e., authentic condition). The researcher hypothesized that participants in the explicit condition would perform better than the participants who were given the authentic condition. The average pre-test score for the authentic condition was 4 and the average post test score was 14. The average pretest score for the explicit condition was 2 and the average posttest score was 14. Average gain scores are recorded in Table 2 and represented graphically in Figure 1.

A one-way analysis of variance (ANOVA) was computed with gain scores as the dependent variable and conditions (i.e., authentic condition or explicit condition) as the factor. The analyses yielded a non-significant effect of condition, $[\mathrm{f}(1,40)=.353, \mathrm{p}=.556]$. The hypothesis that the students would perform better when given the text in an explicit condition, such as a list of vocabulary words was rejected. These findings indicate that students' learning did not differ between conditions. 
Table 1

Demographic Information for Participants

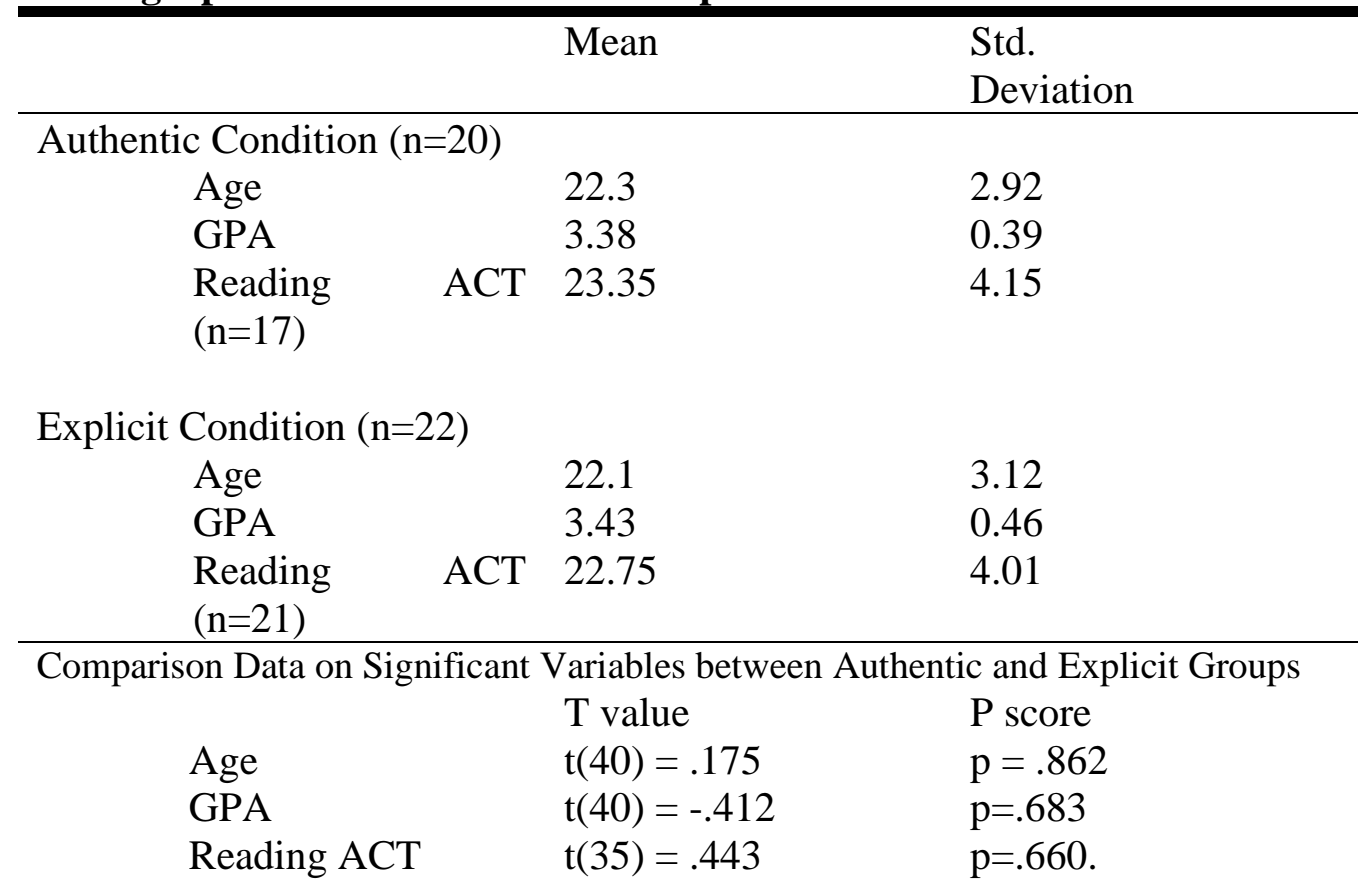

Table 2

Treatment Group Mean Gain Scores and Standard Deviations

\begin{tabular}{|c|c|c|c|}
\hline Condition & $\begin{array}{l}\text { Mean } \\
\text { Score }\end{array}$ & Gain & $\begin{array}{l}\text { Standard } \\
\text { Deviation }\end{array}$ \\
\hline Authentic Condition & 10.7 & & 5.9 \\
\hline Explicit Condition & 12.05 & & 8.4 \\
\hline
\end{tabular}




\section{Figure 1 \\ Dot Plot Graph of Gain Scores}

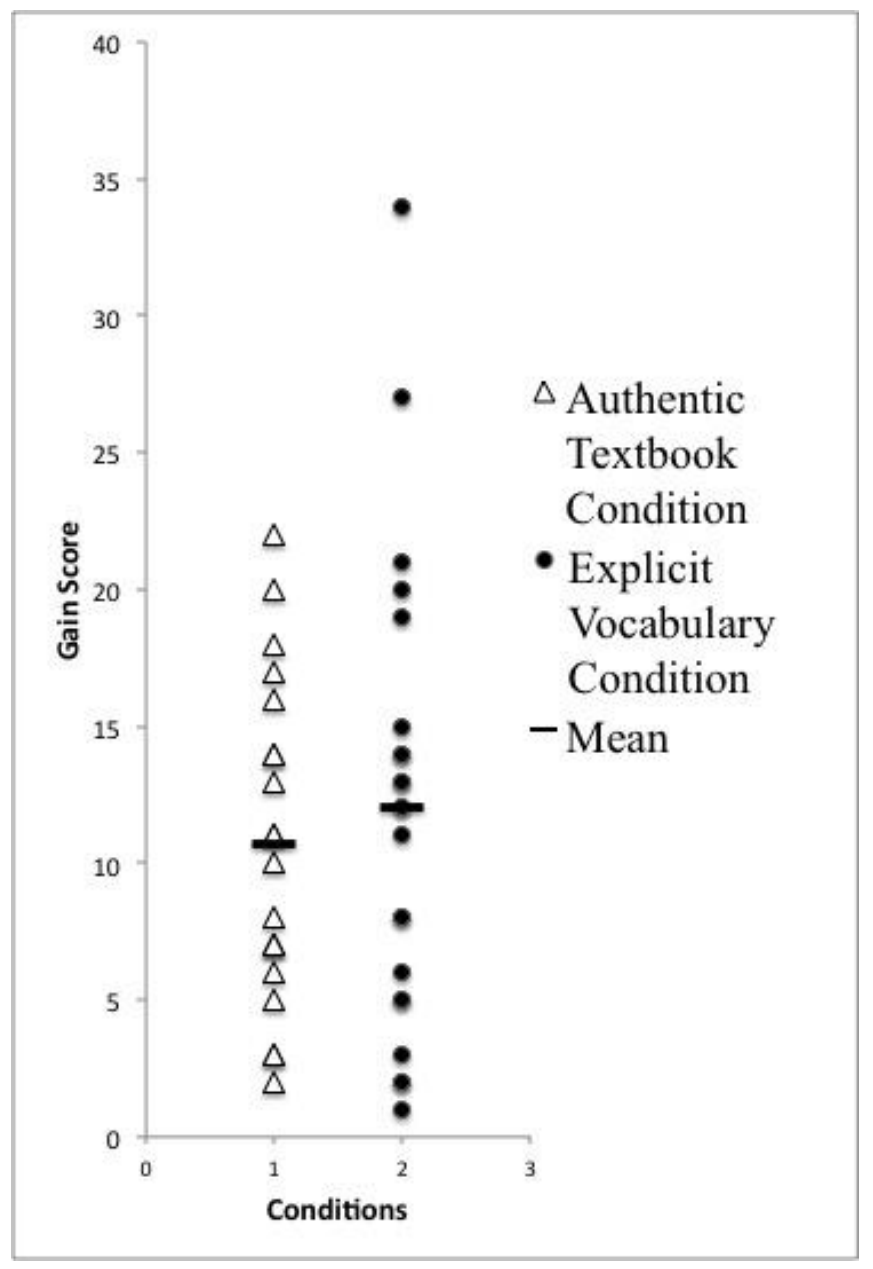

The second research question asked if students with lower reading ACT scores would better match their peers' abilities when given the explicit condition than when given the authentic condition. The researcher hypothesized that in the authentic condition students with low reading ACT scores would perform worse than their peers, but that this difference would be mitigated when the students were given the explicit condition. The gain scores by condition and ACT score are represented in Table 3.

To assess the relationship between ACT score and treatment conditions, an ANCOVA was used with the covariate being reading ACT score and the dependent variable being condition (i.e., authentic and explicit). The analyses yielded a non-significant effect of reading level group, $[\mathrm{f}(2,35)=1.244=\mathrm{p}=.301]$. The results suggest that low readers and high readers responded equally to learning vocabulary regardless of condition. The hypothesis that students with low reading ACT scores would be best served by the explicit condition was not supported. 
Table 3

Gain Scores for students in reading groups

\begin{tabular}{lll}
\hline ACT group & Gain Score & $\begin{array}{l}\text { Standard } \\
\text { Deviation }\end{array}$ \\
\hline $\begin{array}{l}\text { Students with low ACT reading scores, } \leq 22 \\
\text { Authentic Condition }\end{array}$ & 9.25 & 5.7 \\
Explicit Condition & 10.45 & 6.9 \\
& & \\
Students with high ACT reading scores, $>22$ & & 6.9 \\
Authentic Condition & 12.11 & 9.3 \\
Explicit Condition & 14.8 & \\
\hline
\end{tabular}

Analysis of Student Feedback and Student Reading Habits. The researchers collected information about the testing materials and general reading habits in order to further explore these participants' reading experiences. After reading the material, participants were asked to rate its difficulty on a scale of one to five, one being the least difficult and five being the most difficult. Two participants rated it as a one or two. Five participants rated it as a three. The remaining 35 participants rated the information as being a four or five in difficulty level. Similar results were found when the same question was asked of the testing material. The researcher added this question after the testing began, so not all participants received the question, in order to ask about the difficulty of both the reading and the testing. Twenty-nine participants reported that the test was of a four or five in difficulty level (one being the least difficult and five being the most difficult). Seven reported it was a three, and two reported a one. A Pearson product-moment correlation coefficient failed to show a correlation between these difficulty ratings and performance on the task (gain score), material difficulty $[\mathrm{r}=-.205, \mathrm{n}=41, \mathrm{p}=.148]$, test difficulty, $[\mathrm{r}=.013, \mathrm{n}=37$, $\mathrm{p}=.940]$.

The researchers used SPSS to conduct a Pearson product-moment correlation coefficient in order to assess the relationship between ACT score and gain score. The correlation between the two variables did not reach significance $[\mathrm{r}=.239, \mathrm{n}=38, \mathrm{p}=.148]$. A majority of the participants rated the task and reading as difficult.

Additionally, participants were asked three separate questions regarding their preference for learning new vocabulary by having a list of definitions or reading the textbook. These questions were added after data collection began. Therefore, only 38 participants were given the questions. The questions were: (1) "For this material from the anatomy textbook, would you prefer to read from the textbook, or a list of words with their definitions?; (2) In general, would you prefer to read a list of words or a textbook chapter before class?; and (3) Which do you think would be more helpful?" These responses are recorded in Table 4. Participants showed a clear preference for a vocabulary list with definitions compared to reading a textbook passage. A Pearson productmoment correlation coefficient did not reveal correlation between ACT score and perceived difficulty of the testing or reading material, $[\mathrm{r}=.023, \mathrm{n}=35, \mathrm{p}=.896]$. ACT score did not influence preferences. Students from both treatment groups were equally likely to express the difficulty as a 4 out of 5. An independent-samples t-test compared perceived challenge from a Likert scale in the explicit condition $[\mathrm{M}=4.15 \mathrm{SD}=.875]$ and the authentic condition $[\mathrm{M}=4.14 \mathrm{SD}=.964]$. There was 
not a significant difference between the challenge rating between the two groups [t(39), $\mathrm{p}=.980]$. A Pearson product-moment correlation coefficient also did not reveal a correlation between ACT score and interest in the material $[\mathrm{r}=.180, \mathrm{n}=38, \mathrm{p}=.281]$.

\section{Table 4}

Responses to questions on participant preferences

\begin{tabular}{lcc}
\hline Questions & $\begin{array}{c}\text { Number that prefer } \\
\text { Textbook }\end{array}$ & $\begin{array}{c}\text { Number that prefer a } \\
\text { Vocabulary list }\end{array}$ \\
\hline $\begin{array}{l}\text { Preference of textbook or vocabulary } \\
\text { for this information }\end{array}$ & 7 & 31 \\
$\begin{array}{l}\text { Preference of textbook or vocabulary in } \\
\text { general, }\end{array}$ & 7 & 31 \\
$\begin{array}{l}\text { Helpfulness of textbook or vocabulary } \\
\text { in general }\end{array}$ & 8 & 27 \\
\hline
\end{tabular}

Furthermore, participants were asked information about their compliance with reading material in classes by answering one multiple choice question about their habits. They were given the choices: A) I follow the schedule consistently; B) I read the assigned material about half the time; C) I do not follow the schedule, but I do read the textbook; and D) I do not touch my textbook unless necessary. Fifty-two percent responded that they read the material about half the time, and 32\% responded that they follow the reading schedule consistently. Students with low ACT scores (22 and lower) were the only students who reported that they only read the textbook for assignments. See Figure 3.

\section{Figure 3}

\section{Pie Graph of Textbook Habits}

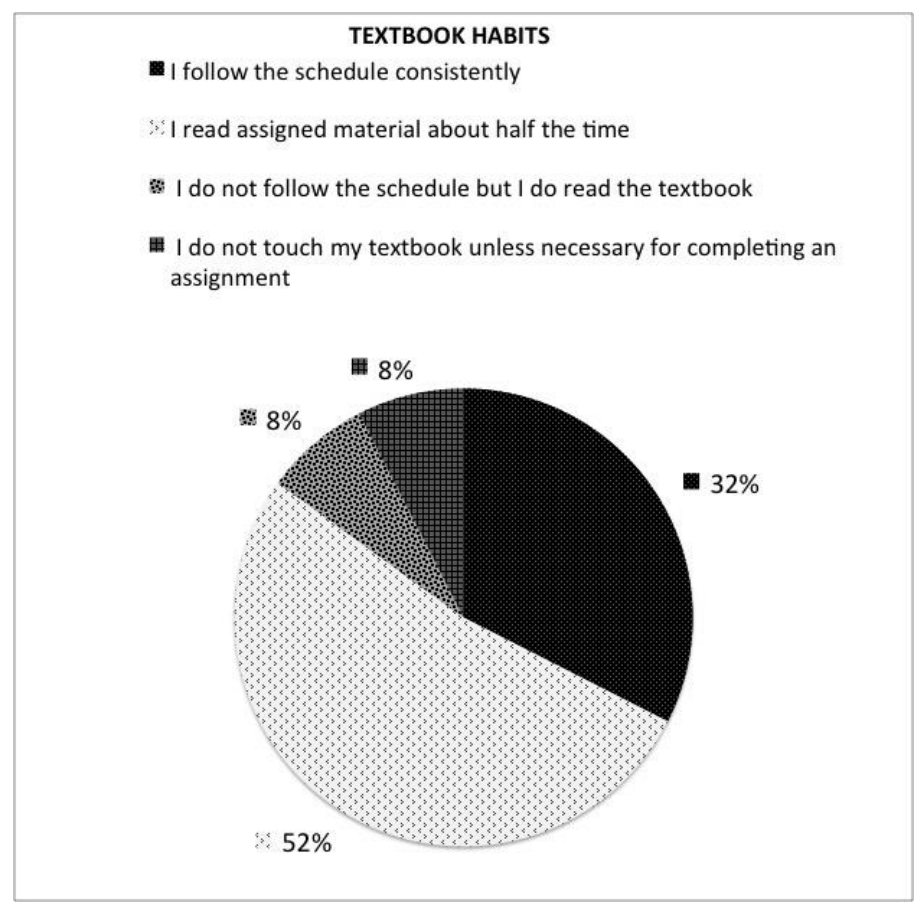




\section{Discussion}

The researchers hypothesized that for the initial exposure of complex material the explicit condition would yield higher vocabulary gains to the traditionally assigned method of a textbook reading; this was intended to give students word knowledge before going to lecture. The researchers also hypothesized that this method would equalize performance gains for those with higher versus lower reading ACT scores. The research results failed to show significance; therefore, the hypotheses were not supported.

The researchers found that the performance for both conditions was low, but with wide variability. Fifteen participants had gain scores of less than ten. Since the participants were instructed to read the material only one time, it is not surprising their performance was low. The material was highly complex, and the amount of information that can be retained from one repetition is limited. Poor recall after reading from a textbook has been found in other studies as well. In a study on reading compliance in a university's first year seminar classes, students were given an anonymous survey at the beginning of one class to see if they had read the assignment. Fifty-five percent of students reported that they had read the assignment, yet only $25 \%$ produced a summary statement based on the relevant material (Hoeft, 2012). Poor performance on the task has implications for the classroom. Textbook and vocabulary assignments may simply be inadequate, or students may not be motivated to complete them. If textbooks and vocabulary assignments are outside of the students' abilities, then poor performance is expected. This explanation may also indicate that students are not reading because they are not able to independently understand the material.

One other substantial possibility is that many students are simply not reading with adequate focus and motivation. This is supported by the high variability in the study. The top gain score was a 34 while the lowest was a 1 . This large difference more likely reflects varying student engagement and attention than it does the cognitive ability. Haussamen (1995) says that this phenomenon is often described as "passive reading," and he argues that inattentiveness is the primary cause (p. $381)$.

The study revealed a second problem in that half of the students reported that they read the assigned material about half the time before attending class. Professors likely believe that reading assignments lead to better course grades, and therefore, poor grades are the natural consequence of failing to read textbook material. However, students with both high and low GPAs do not comply with reading assignments (Phillip \& Phillips, 2007). Researchers described this finding as "permissive acceptance of noncompliance" (Burchfield, \& Sappinton, 2000, p. 59).

If reading the textbook is considered optional, then students will not complete the assignment. Unless "reading to learn" is required of the student, reading assignments will always be what one researcher described as "a carrot and stick approach" (quoted in Burchfield \& Sappington, 2000). If a professor decides that a textbook assignment is necessary before class, professors must clearly outline the extent to which students are expected to learn independently from textbooks, and then hold students accountable for that information.

The results from this study reveal problems that professors may wish to address. Activities that 
lead to compliance, which includes increased attention and effort, also boost reading achievement. Research done on a university wide initiative at Fayetteville State University encouraged faculty to assess the reading ability of their students early in the semester. Then during the semester professors were expected to instruct on three reading strategies. These included summaries, textual analysis, journal entries, and interpretations of quotes (Anderson \& Kim, 2011). The classes had an average of $38.8 \%$ growth in reading comprehension skills in the genre from the beginning to the end of the semester, with a maximum growth of 78.6\% (Anderson \& Kim, 2011). Strategies such as journal entries require students to reflect on the material as well as their perceived comprehension of the material.

Research indicates four methods that teachers can enlist to increase participation in reading assignments. Teachers who wish to tackle inattention during reading could implement graded journals, quizzes, summaries, and pre-assigned questions (Hoeft, 2012; Delong \& Winter, 2002). Frequent random quizzes have been shown to dramatically improve reading compliance. Compliance jumped from $46 \%$ compliant to $76 \%$ compliant in a public speaking course (Hoeft, 2012). Graded journals proved the best method to increase compliance; however, performance on a recall assignment was higher with quiz assignments (Hoeft, 2012). Other measures may include having the students submit reading summaries, or pre-assign questions for students to answer from the reading (Delong \& Winter, 2002). All activities that require the student to engage with the text increase their involvement with novel words, a necessary component of word learning (Nagy \& Townsend, 2012). In addition to any assignments associated with reading, educators should clearly define realistic goals for reading assignments that they explicitly tell the students from the beginning of the semester. For example, they should inform the student to read the material in such a way that they could provide a summary and define the novel words in the passage (Delong \& Winter, 2002).

\section{Limitations of the Study}

The current study has four design flaws that impacted the results and their interpretation. First, the researcher neglected to consider the amount of time-on-task. Time-on-task is a potentially confounding variable in many educational research studies (Simmons, 1983). The researcher did not collect data or control for time-on-task, but it likely influenced performance. Time-on-task would have further informed the research because it most likely is directly correlated with performance on the study, which may have directed future questions about the way that students read. Time-on-task may have been shorter for students who received the explicit condition since they only had to read the term and its definition, which could explain why students stated that they would prefer to read definitions.

Second, the study did not provide the participants with specific instructions and expectations. The researcher instructed the participants to read through the packet one time and then inform the researcher when they were finished. The instructions did not indicate that students were expected to memorize or learn the information at hand. Some students expressed surprise when the test itself was so difficult, while others predicted that the pre- and post-test were the same. Instructions that asked the participants to read to learn the material, and explicitly explained the definition in the post-test, might have led to better performance results. 
Third, the material targeted 25 words and identified 70 pieces of relevant information for those words. The test used to assess the participants' understanding did not contain visual or contextual supports. The feedback from the participants consistently reflected that the test was hard. This problem could be addressed by allowing multiple exposures, and giving students supports, such as matching or multiple choices, or emphasizing that the information is hard, but that effort is appreciated.

Fourth, the survey material may have been influenced by the condition that the participant received. If the participant received the textbook material, it may have caused them to choose differently than the vocabulary condition about their general regard to textbooks.

A final limitation is lack of incentive for participants to perform their best on the task. The primary researcher identified effort as a significant variable data during data collection. For example, one student had come in after an all-nighter of studying and was particularly worried about skewing the data down and, "messing up your project." This student, presumably to compensate for her lack of sleep, had higher accuracy than other participants. Future research should incentivize performance on the test via extra credit points, or differential monetary compensation. In other education research, researchers used deception by telling the participants that their compensation would vary based on performance, however; participants received equal compensation at the end.

In summary, future research should use methodology that controls for time-on-task, gives specific instructions, uses tests that utilize some type of visual or textual support, and incentives for test performance.

\section{Conclusion}

The results of the study revealed no significant differences between participants who were in conditions that received vocabulary words within the context of a textbook or isolated in a list. However, when asking the participants their preferred learning mode (i.e., textbook versus vocabulary list), a majority of them opted for the word list, which provides insight to students' learning preferences. The participant performance yielded wide variability, which is not surprising since the content was challenging. Future researchers should address the initial research questions by incorporating methodology that controlled and/or measured time-on-task with more specific instructions and increased incentives to produce intentional effort.

\section{Disclosures}

The authors do not have any additional financial or nonfinancial disclosures to report.

\section{References}

Aagaard, L., Conner, T. I., \& Skidmore, R. L. (2014). College textbook reading assignments and class time activity. Journal of the Scholarship of Teaching and Learning, 14(3), 132-145.

Anderson, T., \& Kim, J. Y. (2011). Strengthening college students' success through the reading across the curriculum. Journal of College Reading and Learning, 42(1), 61-78.

American Speech-Language-Hearing Association Roles and Responsibilities of SLPs in Schools 
Working Groups (2012). ASHA Roles and Responsibilities of Speech-Language Pathologists (SLPS) in Schools Dos and Don'ts. Retrieved from http://www.asha.org/uploadedFiles/Roles-Responsibilities-SLP-Schools-DOs-andDONTs.pdf

Baer, J. D., Cook, A. L., \& Baldi, S. (2006). The literacy of America's college students. Washington, DC: American Institutes for Research.

Bartolomeo-Maida, M. (2016). The use of learning journals to foster textbook reading in the community college psychology class. College Student Journal, 50(3), 440-453.

Berry, T., Cook, L., Hill, N., \& Stevens, K. (2011). An exploratory analysis of textbook usage and study habits: Misperceptions and barriers to success. College Teaching, 59(1), 31-39.

Burchfield, C. M., \& Sappington, J. (2000). Compliance with required reading assignments. Teaching of Psychology, 27(1). 58-60.

Burton, R. S. (2014). Readability, logodiversity, and the effectiveness of college science textbooks. Bioscene: Journal Of College Biology Teaching, 40(1), 3-10.

Chall, J. (1996). American reading achievement: Should we worry? Research in the Teaching of English, 30(3), 303-310.

Council for Clinical Certification in Audiology and Speech-Language Pathology. (2016). 2014 Standards and Implementation Procedures for the Certificate of Clinical Competence in Speech-Language Pathology. Retrieved from http://www.asha.org/Certification/2014Speech-Language-Pathology-Certification-Standards/

Cowan, N. (2014). Working memory underpins cognitive development, learning, and education. Educational Psychology Review, 26(2), 197-223.

DeLong, M., \& Winter, D. (2002). Getting students to read the textbooks. In Learning to Teach and Teaching to Learn Mathematics (pp. 55 - 64). Washington, D.C: Mathematical Association of America. Retrieved from http://www.jstor.org/stable/10.4169/j.ctt5hh8n9

Haussamen, B. (1995). The Passive-Reading Fallacy. Journal of Reading, 38(5), 378-381. Retrieved from http://www.jstor.org/stable/40033254

Heiner, C. E., Banet, A. I., \& Wieman, C. (2014). Preparing students for class: How to get $80 \%$ of students reading the textbook before class. American Journal Of Physics, 82(10), 989. doi:10.1119/1.4895008

Hoeft, M. M. (2012). Why university students don't read: What professors can do to increase compliance. International Journal For The Scholarship Of Teaching \& Learning, 6(2), 119.

Laufer, B., \& Ravenhorst-Kalovski, G. C. (2010). Lexical threshold revisited: Lexical text coverage, learners' vocabulary size and reading comprehension. Reading in a Foreign Language, 22(1), 15-30.

Mayer, R. E., Bove, W., Bryman, A., Mars, R., \& Tapangco, L. (1996). When less is more: Meaningful learning from visual and verbal summaries of science textbook lessons. Journal of Educational Psychology, 88(1), 64-73.

Nagy, W., \& Townsend, D. (2012). Words as tools: Learning academic vocabulary as language acquisition. Reading Research Quarterly, 47, 91-108. doi:10.1002/RRQ.011

Ornstein, A. (1994). The textbook-driven curriculum. Peabody Journal of Education, 69(3), 7085.

Phillip, B. J., \& Phillips, F. (2007). Sink or skim: Textbook reading behaviors of introductory accounting students. Issues in accounting education, 22(1), 21-44.

Sanchez, C. (2013). College board concerned about low SAT scores. In NPR (Producer) All things 
considered. Retrieved from

http://www.npr.org/2013/09/26/226530184/college-board-concerned-about-low-satscores.

Schoerning, E. (2014). The effect of plain-English vocabulary on student achievement and classroom culture in college science instruction. International Journal Of Science \& Math Education, 12(2), 307-327.

Seikel, J. A., Drumright, D., \& King, D.W. (2016). Physiology of articulation and resonation. Anatomy \& Physiology for Speech, Language and Hearing (5th ed.). Clifton Park, NY: Cengage Learning.

Snowman, J., Leitner, D. W., Snyder, V., \& Lockhart, L. (1980). A comparison of the predictive validities of selected academic tests of the American College Test (ACT) assessment program and the descriptive tests of language skills for college. Educational \& Psychological Measurement, 40(4), 1159-1166.

Simmons, P. R. T. (1983). How we should control time on task - or should we? Instructional Sciences, 11(4), 357-372.

Skinder-Meredith, A. E. (2010). Innovative activities for teaching anatomy of speech production. Anatomical Sciences Education, 3(5), 234-243.

Stiggins, R. J., Schmeiser, C. B., \& Ferguson, R. L. (1978). Validity of the ACT assessment as an indicator of reading ability. Applied Psychological Measurement, 2(3), 339-346.

Turnbull, W. W. (1985). Student change, program change: Why the SAT scores kept falling (College Board Report No. 85-2 ETS RR No. 85-28). New York, NY: College Entrance Examination Board.

Zygouris-Coe, V., \& Goodwiler, C. (2013). Language and literacy demands of content area courses in the era of the Common Core State Standards: Teachers' perspectives and the role of the SLP. Perspectives On School-Based Issues, 14(3), 61-67. 